\title{
Affinity selection and sequence- activity relationships of HIV-1 membrane fusion inhibitors directed at the drug-resistant variants
}

\section{$\operatorname{AUTHOR}(S)$ :}

Oishi, Shinya; Watanabe, Kentaro; Ito, Saori; Tanaka, Michinori; Nishikawa, Hiroki; Ohno, Hiroaki; Shimane, Kazuki; ... Matsuoka, Masao; Asai, Akira; Fujii, Nobutaka

\section{CITATION:}

Oishi, Shinya ... [et al]. Affinity selection and sequence-activity relationships of HIV-1 membrane fusion inhibitors directed at the drug-resistant variants. MedChemComm 2010, 1(4): 276-281

\section{ISSUE DATE:}

2010

URL:

http://hdl.handle.net/2433/126711

\section{RIGHT:}

(C) 2010 Royal Society of Chemistry; 許諾条件により本文は2011-07-22に 公開.; This is not the published version. Please cite only the published version.; この論文は出版社版でありません。引用の際には出版社版を ご確認ご利用ください。 


\section{Affinity selection and sequence-activity relationships of HIV-1 membrane fusion inhibitors directed at the drug-resistant variants}

Shinya Oishi, ${ }^{* a}$ Kentaro Watanabe, ${ }^{a}$ Saori Ito, ${ }^{a}$ Michinori Tanaka, ${ }^{a}$ Hiroki Nishikawa, ${ }^{a}$ Hiroaki

Ohno, ${ }^{a}$ Kazuki Shimane, ${ }^{b}$ Kazuki Izumi, ${ }^{b}$ Yasuko Sakagami, ${ }^{b}$ Eiichi N. Kodama, ${ }^{b, d}$ Masao Matsuoka, ${ }^{b}$ Akira Asai, ${ }^{c}$ and Nobutaka Fujii* ${ }^{a}$

${ }^{a}$ Graduate School of Pharmaceutical Sciences, Kyoto University, Sakyo-ku, Kyoto 606-8501, Japan

${ }^{b}$ Laboratory of Virus Control, Institute for Virus Research, Kyoto University, Sakyo-ku, Kyoto 6068507, Japan

${ }^{c}$ Graduate School of Pharmaceutical Sciences, University of Shizuoka, Suruga-ku, Shizuoka $422-$ 8526, Japan

${ }^{d}$ Present address: Division of Emerging Infectious Diseases, Tohoku University School of Medicine, Sendai 980-8575, Japan

*Corresponding Authors:

Shinya Oishi, Ph.D. and Nobutaka Fujii, Ph.D.

Graduate School of Pharmaceutical Sciences

Kyoto University

Sakyo-ku, Kyoto, 606-8501, Japan

Tel: +81-75-753-4551, Fax: +81-75-753-4570,

E-mail (S.O.): soishi@pharm.kyoto-u.ac.jp; E-mail (N.F.): nfujii@pharm.kyoto-u.ac.jp 
Summary. Enfuvirtide is the first approved membrane fusion inhibitor against HIV-1. Although this drug is effective against multi-drug resistant strains, the emergence of enfuvirtide-resistant strains has been reported in patients who have received an enfuvirtide-containing regimen. Based on the high affinity of synthetic HIV-1 gp41 C-terminal heptad repeat (C-HR) peptides to the counterpart trimeric N-terminal heptad repeat (N-HR) coiled-coil structure, a novel screening approach has been established to facilitate the identification of potent fusion inhibitors against wildtype and enfuvirtide-resistant HIV-1. In this process, affinity selection using histidine-tagged N-HR peptides with the sequences derived from wild-type and resistant strains efficiently captured potent inhibitory peptides from a pool of highly water-soluble C-HR peptides with $\alpha$-helix-inducible motifs. A highly potent peptide was found from a single amino acid substitution observed in an enfuvirtide-resistant variant as well as peptides with unprecedented modifications at the mutated site.

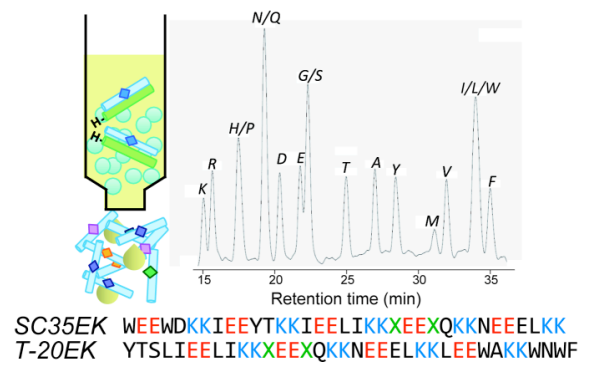




\section{Introduction}

Several inhibitors that block viral attachment and the fusion process have been approved for the treatment of human immunodeficiency virus (HIV) in the past decade. The first fusion inhibitor, enfuvirtide (T-20), binds to the N-terminal heptad repeat (N-HR) of the HIV-1 envelop glycoprotein gp41, ${ }^{1}$ and prevents the formation of a fusogenic anti-parallel coiled-coil structure (known as the six-helical bundle) between N-HR and the C-terminal heptad repeat (C-HR) (Figure 1a). ${ }^{2}$ Enfuvirtide is effective even against the clinical strains that are resistant to multiple drug classes such as reverse transcriptase inhibitors and protease inhibitors used in highly active antiretroviral therapy (HAART). However, the emergence of enfuvirtide-resistant strains has been reported in patients receiving long-term enfuvirtide treatment. ${ }^{3,4}$

The primary evolution of enfuvirtide resistance occurs on gp41 N-HR, which attenuates the binding affinity with enfuvirtide, resulting in decreased drug susceptibility. ${ }^{3-5}$ The major primary mutations are V38A and N43D in the Leu33-Leu45 region of N-HR. These mutations subsequently lead to a secondary mutation appearing in C-HR, which can compensate the binding affinity between viral N-HR and C-HR for efficient gp41 folding. ${ }^{6}$ For example, N126K and S138A mutations have been reported to enhance the resistance induced by enfuvirtide and another inhibitory C-HR peptide, C34. These complementary mutations, which occur at the face-to-face positions of N-HR and C-HR verified by crystallographic studies, ${ }^{7-9}$ can restore the critical step required for viral infection into the target cells and eliminate the inhibitory effect of exogenous enfuvirtide. Recently, several novel fusion inhibitors such as tifuvirtide (T-1249) ${ }^{10}$ and sifuvirtide, ${ }^{11}$ which are effective against these enfuvirtide-resistant viruses, have been reported. We have also demonstrated a novel tailored design of fusion inhibitors based on the enfuvirtide-resistant mutation to preempt this escape strategy of HIV $-1 .{ }^{12}$ Enfuvirtide analogues carrying a substitution corresponding to the secondary mutation were found to exert potent anti-HIV activity against wildtype and enfuvirtide-resistant strains with the primary mutations. Of interest, during this observation, we found that enfuvirtide analogues with other substitutions were also effective against these strains. Alternatively, modification of a single residue in C-HR such as Q141L, which is involved in the increased syncytium-forming ability of the mutant virus, ${ }^{13}$ led to an increase in the anti-HIV potency of inhibitor C34. ${ }^{14}$ These observations implied that the C-HR sequence with substitutions, which were not spontaneously elaborated by single nucleotide mutations from wild- 
type HIV-1, could represent potent fusion inhibitors. Encouraged by these results, the optimization of interactive residues of fusion inhibitors against wild-type and enfuvirtide-resistant viruses was undertaken.

Affinity selection-mass spectrometry (AS-MS) is a promising methodology for compound screening, in which target molecule-bound components are captured from a pool of candidates and are identified by mass spectrometry. The successful applications of this technique are exemplified by the identification of kinase inhibitors ${ }^{15}$ and antifungal natural products. ${ }^{16}$ This simple selection process by virtue of the binding affinity can be a facile alternative to functional bioassays, although the functions and mechanisms of captured compounds for bioactivity cannot be determined. For medicinal chemistry of HIV fusion inhibitors, this approach should be suitable in the optimization of inhibitory C-HR peptides such as T-20EK ${ }^{17}$ and SC35EK. ${ }^{18}$ Taking advantage of the trimeric NHR coiled-coil as a target molecule, a mixture of C-HR peptides with a single amino acid substitution can be screened without using recombinant or clinical HIV strains. ${ }^{19,20}$ We envisioned that the competitive binding of C-HR components would capture relatively more potent anti-HIV peptides with higher affinity towards N-HR. Herein we report on the affinity-based screening technology and sequence-activity relationships for amino acid optimization in HIV-1 fusion inhibitors directed against enfuvirtide-resistant HIV strains.

\section{Results and Discussion}

T-20EK and SC35EK are characterized by repeated X-EE-XX-KK motifs that stabilize the bioactive $\alpha$-helix structure of enfuvirtide and C34, respectively (Figure 1a). Potential electrostatic interactions between glutamic acid (Glu) and lysine (Lys) residues at $i$ and $i+4$ positions, respectively, are distinct from the traditional stabilization with stapled covalent linkages. ${ }^{21,22}$ Consistent substitution of the residues located on the non-interactive surface of the C-HR $\alpha$-helix with Glu or Lys achieved an enhancement in affinity toward the N-HR sequence and anti-HIV activity. This process disclosed the indispensable residues in C-HR for direct interaction with viral N-HR (Figure 1b). ${ }^{23}$ Additionally, in contrast to native sequences of C-HR peptides that are highly hydrophobic, substitution with charged amino acids markedly improved the aqueous solubility of the peptides. This design allowed us to prepare a homogeneous mixture of the SC35EK derivatives and T-20EK derivatives at high concentrations. 
Initially, C-HR peptide libraries with a variety of canonical amino acid substitutions at the positions to be optimized (Ser138 and Gln141) were prepared by a split-pool method. After the construction of the C-terminal sequence using a standard Fmoc-based solid-phase peptide synthesis approach, the resin was split into fractions at position 138 or 141, where proteinogenic amino acids except for cysteine were coupled in parallel. The 19 fractions were combined again and the Nterminal sequence was constructed in one portion. All the protected peptide resins were treated with a cocktail of deprotection reagents, and the crude peptides were purified by reversed-phase HPLC to afford the expected peptides.

Separately, in order to rationalize the selection process by affinity-based technology and to investigate the sequence-activity relationship, all C-HR peptides with a single substitution were prepared in parallel and were evaluated for the biological and physicochemical properties individually. The counterpart N-HR peptides of the wild-type and enfuvirtide-resistant variants (V38A and N43D) were also prepared. For affinity selection, the histidine tag $\left(\mathrm{His}_{6}\right)$ sequence of the N-HR peptides was attached on the N-terminus via an aminocaproic acid-glycine dipeptide linker. This linker was incorporated to avoid the possible disruption of N-HR and C-HR interaction by positively charged $\mathrm{His}_{6}$-tag. Anti-HIV activities of all the C-HR peptides against laboratory wild-type $\mathrm{HIV}-1_{\mathrm{NL4-3}}$ or the variants with enfuvirtide-resistant mutations were evaluated using the MAGI assay. Thermal stabilities of the potential six-helical bundles consisting of N-HR and C-HR peptides were evaluated by measuring the melting temperature $\left(T_{\mathrm{m}}\right)$ using the molar ellipticity value at $222 \mathrm{~nm}$ in circular dichroic (CD) spectra of N36/SC35EK or N54/T-20EK mixture (Figure S1).

The AS-MS protocol was optimized using SC35EK derivatives (Table 1). A pool of SC35EK $_{\text {S138X }}$ was incubated with a wild-type N-HR peptide, N36 (10 $\left.\mu \mathrm{M}\right)$ with an N-terminal His $6^{-}$ tag, in HEPES buffer ( $\mathrm{pH}$ 7.4). The potential six-helical bundles of N36-SC35EK $\mathrm{S138 \textrm {X }}$ were captured by Ni-NTA agarose resin and were subsequently eluted with $50 \%$ AcOH (Figure $2 \mathrm{a}$ ). The captured components were separated and characterized by LC-MS analysis, except that the peptides with Leu and Ile were observed as overlapping peaks of the same mass-to-charge ratio (Figure $2 b$ ). The recovery rate in affinity selection for relative binding ability to N36 was calculated from the detected signal of $[\mathrm{M}+3 \mathrm{H}]^{3+}$ and $[\mathrm{M}+4 \mathrm{H}]^{4+}$ ions of each C-HR peptide by the LC-MS analysis of captured peptides. Under the high concentration conditions (10 $\mu \mathrm{M}$ each of SC35EK $\mathrm{S} 138 \mathrm{X})$, several potent peptides including a resistant variant-derived S138A peptide were captured in high recovery 


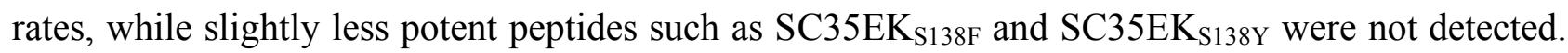
In contrast, when the total concentration of the mixture was nearly equal to the N36 concentration $\left(0.6 \mu \mathrm{M}\right.$ each of $\left.\mathrm{SC} 35 \mathrm{EK}_{\mathrm{S} 138 \mathrm{X}}\right)$, there was no discernible difference in the recovery rates of each peptide. The compound with the least potent anti-HIV activity in the series, SC35EK $\mathrm{S}_{\mathrm{S} 138 \mathrm{R}}$, was recovered under this equimolar concentration conditions. This recovery suggested that the method is not effective under lower concentration conditions of C-HR peptides. A condition using $1 \mu \mathrm{M}$ each of SC35EK $\mathrm{S}_{138 \mathrm{X}}$ (total $19 \mu \mathrm{M}$ of the mixture) for affinity selection was selected for further experiments, in which the recovery rate was found to positively correlate with the stability of the six-helical bundle (Figure 3a). Although an ideal linear correlation was not observed between the logarithmic $\mathrm{EC}_{50}$ of anti-HIV activity and the recovery rate (Figure $3 \mathrm{~b}$ ), the peptides, which were captured in relatively high yields by affinity selection, exhibited highly potent anti-HIV activity.

The optimized condition was applied for the selection of T-20EK $\mathrm{E}_{\mathrm{S} 138 \mathrm{X}}$ derivatives (Table 2). The anti-HIV activity of T-20EK $\mathrm{E}_{\mathrm{S} 138 \mathrm{X}}$ was found to be dependent on the amino acid type at position 138. Substitution with aliphatic side-chain amino acids such as Ala, Ile, Leu, Met and Val, displayed highly potent anti-HIV activity, although significant stabilization of the N54-T-20EK $\mathrm{E}_{\mathrm{S} 138 \mathrm{X}}$ complexes was not observed. Gly- and Thr-substitutions were also observed to increase potency. In contrast, hydrophilic, charged and aromatic amino acid substitutions at position 138 reduced binding with N54. In our previous study, it was demonstrated that higher affinity with the N-HR sequence and more potent anti-HIV activity of $\mathrm{C} 34_{\mathrm{S} 138 \mathrm{~A}}$ and $\mathrm{T}-20_{\mathrm{S} 138 \mathrm{~A}}$ were due to the dominant contribution of larger desolvation free energy of the hydrophobic side-chain. ${ }^{8}$ The structure-activity relationship of $\mathrm{T}-20 \mathrm{EK}_{\mathrm{S} 138 \mathrm{X}}$ can be partially rationalized by the similar hydrophobic/hydrophilic properties of the side-chain. The recovery rates of T-20EK $\mathrm{S} 138 \mathrm{X}_{\mathrm{X}}$ in affinity selection showed good correlations with both anti-HIV activity and with thermal stability of the complexes (Figures $3 \mathrm{c}$ and $3 \mathrm{~d})$. The peptides captured with more than $9 \%$ recovery yields exhibited sub-nanomolar potency along with $T_{\mathrm{m}}$ values $>75^{\circ} \mathrm{C}$.

The anti-HIV activities of the series of peptides against recombinant viruses with either the enfuvirtide-resistant V38A or N43D mutation in N-HR were evaluated. The results of representative C-HR peptides, which were obtained by a single nucleotide mutation of HIV-1 ${ }_{\mathrm{NL4}-3}$, are shown in Table 3 and Figure S2. From Ser138 encoded by the TCG codon in wild-type NL4-3, Ala (GCG), Pro (CCG), Thr (ACG), Leu (TTG) and Trp (TGG) are possible mutations; the other 
mutations are silent (TCA, TCT, TCC) or a stop codon (TAG). The S138A substitution in both SC35EK and T-20EK enhanced the thermal stability of the N-HR/C-HR complex, indicating that this is a favorable mutation in terms of gp41 folding of the resistant virus. ${ }^{3,4}$ These peptides by mutant-directed design restored and enhanced the anti-HIV activity against enfuvirtide-resistant variants. The S138L peptide was also effective against both V38A and N43D strains; however, no emergence of a clinical variant having this mutation has been reported. Of interest, resistant viruses are unlikely to necessarily use the best C-HR substitution to complement the gp41 folding, presumably due to the low replication kinetics. These results indicate that the mutations observed in clinical variants can direct the position to be optimized for inhibitor design but not the most appropriate amino acids. In practice, several other substitutions by Ile and Met, which are irrelevant to single nucleotide mutations from the wild-type, also provided potent anti-HIV activity against the resistant strains (Table S4). In contrast, substitution with Pro or Trp for both peptides significantly decreased the activity, which is consistent with the results against the wild-type virus. Lower stabilities of the six-helical bundle structure consisting of S138T peptides and mutant N-HR peptides were shown, but $\mathrm{SC} 5 \mathrm{EK}_{\mathrm{S} 138 \mathrm{~T}}$ was slightly more potent against both resistant viruses compared with the parent peptide.

Using His-tagged N36 or N54 peptides with the V38A or N43D mutation, affinity selection

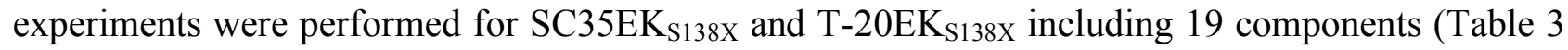
and Table S4). Eight SC35EK derivatives captured in significantly high yields all showed potent anti-HIV activity against the V38A mutant. Moderate recovery yields of $\mathrm{SC}_{35 \mathrm{EK}} \mathrm{S} 138 \mathrm{E}$ and

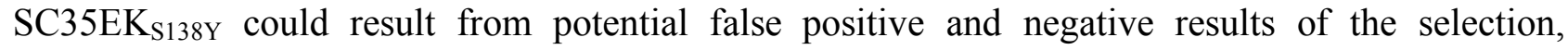
respectively. Although T-20EK derivatives showed lower susceptibility against the V38A mutant in the MAGI assay, an association between the high recovery rate and more potent anti-HIV activity was observed such as S138A, S138I, S138L and S138M derivatives (Figures S3). Similar correlations were also obtained against N43D variants. SC35EK $\mathrm{E}_{\mathrm{S} 138 \mathrm{X}}$ and $\mathrm{T}-20 \mathrm{EK}_{\mathrm{S} 138 \mathrm{X}}$ components, which exhibited subnanomolar potent bioactivity, were recovered in moderate to good yields. Overall favorable amino acids for position 138 of the wild-type were useful for designing C-HR peptides against V38A and N43D variants and vice versa, suggesting that the essential binding mode around this position is conserved even after acquiring the enfuvirtide resistance. 
The structure-activity relationships of Q141 modifications were also investigated (Table 4). All SC35EK $\mathrm{Q}_{\mathrm{Q} 141 \mathrm{X}}$ and $\mathrm{T}-20 \mathrm{EK}_{\mathrm{Q} 141 \mathrm{X}}$ peptides except for the Q141P substitution exhibited similar antiHIV activity in the $\mathrm{EC}_{50}$ range of 1.6-3.2 $\mathrm{nM}$ and $0.51-4.6 \mathrm{nM}$, respectively. The significantly low $T_{\mathrm{m}}$ values of Q141P derivatives suggested that the sole proline residue precluded the formation of a bioactive $\alpha$-helix structure. On the other hand, high potency of the other peptides independent of any other acyclic amino acid substitution at position 141 may be attributable to the lower importance of the Q141 position for the binding affinity between N-HR and C-HR than the S138 position. Among these, Q141I, Q141L and Q141M peptides formed slightly more stable complexes with N36 or N54 and were captured at a relatively higher recovery rate by affinity selection. These substitutions were found to contribute to subnanomolar anti-HIV activity of T-20EK derivatives; however, these peptides were less valid for SC35EK derivatives.

For both S138 and Q141 substitutions, it does not seem possible to distinguish between variations of a few nM in anti-HIV activity by affinity selection. This is particularly the case for the selections regarding less effective residues such as Q141 of SC35EK. In contrast, over a larger range of more than 2 orders of magnitude of affinity variations of T-20EK derivatives, the selection procedure correlated reasonably well with the anti-HIV activity and six-helix bundle stability. In both sequences, highly potent anti-HIV activity peptides were captured in good to high yields.

\section{Conclusions}

In conclusion, we have presented an affinity selection-mass spectrometry method to explore novel HIV-1 fusion inhibitors. Predicated on previous findings that the introduction of $\alpha$-helix-inducible X-EE-XX-KK motifs into inhibitory C-HR peptides should improve peptide solubility in aqueous buffers and disclose the interactive surface to be optimized, a pool of SC35EK and T-20EK derivatives with a single modification at two interactive positions were screened using N-HR peptides corresponding to wild-type and enfuvirtide-resistant strains. Through the screening of position 138 on $\mathrm{C}-\mathrm{HR}$, it was demonstrated that potent anti-HIV peptides could be obtained by substitutions with resistance-related and resistance-independent amino acids. Since a wide variety of synthetic peptides with any unnatural amino acids or peptidomimetics could be employed as candidate components, the system should be applicable to screening for inhibitory $\alpha$-helix peptides of coiled-coil interactions. The structure-activity relationships of C-HR peptides presented herein 
may also be suitable in the design of the next-generation of fusion inhibitors. Additionally, since this process is considered to reproduce the evolutionary process of HIV-1 gp41 to select the appropriate folding partners in the presence of fusion inhibitors, the sequence-activity relationships could facilitate understanding of the underlying mechanisms of enfuvirtide resistance.

\section{Acknowledgements}

This work was supported by the Science and Technology Incubation Program in Advanced Regions from the Japan Science and Technology Agency, Grants-in-Aid for Scientific Research and Targeted Proteins Research Program from the Ministry of Education, Culture, Sports, Science, and Technology of Japan, and Health and Labour Sciences Research Grants (Research on HIV/AIDS). H.N. is grateful for the JSPS Research Fellowships for Young Scientists. 


\section{References}

1. T. Matthews, M. Salgo, M. Greenberg, J. Chung, R. DeMasi and D. Bolognesi, Nat. Rev. Drug Discov. 2004, 3, 215-225.

2. D. C. Chan and C. T. Chutkowski, P. S. Kim, Proc. Natl. Acad. Sci. USA. 1998, 95, 1561315617.

3. L. Xu, A. Pozniak, A. Wildfire, S. A. Stanfield-Oakley, S. M. Mosier, D. Ratcliffe, J. Workman, A. Joall, R. Myers, E. Smit, P. A. Cane, M. L. Greenberg and D. Pillay, Antimicrob. Agents Chemother. 2005, 49, 1113-1119.

4. L. Pérez-Alvarez, R. Carmona, A. Ocampo, A. Asorey, C. Miralles, S. Pérez de Castro, M. Pinilla, G. Contreras, J. A. Taboada and R. Nájera, J. Med. Virol. 2006, 78, 141-147.

5. D. Eggink, J. P. Langedijk, A. M. Bonvin, Y. Deng, M. Lu, B. Berkhout and R. W. Sanders, J. Biol. Chem. 2009, 284, 26941-26950.

6. D. Nameki, E. Kodama, M. Ikeuchi, N. Mabuchi, A. Otaka, H. Tamamura, M. Ohno, N. Fujii and M. Matsuoka, J. Virol. 2005, 79, 764-770.

7. D. C. Chan, D. Fass, J. M. Berger and P. S. Kim, Core structure of gp41 from the HIV envelope glycoprotein, Cell 1997, 89, 263-273.

8 T. Watabe, Y. Terakawa, K. Watanabe, H. Ohno, H. Nakano, T. Nakatsu, H. Kato, K. Izumi, E. Kodama, M. Matsuoka, K. Kitaura, S. Oishi and N. Fujii, J. Mol. Biol. 2009, 392, 657-665.

9 K. Izumi, S. Nakamura, H. Nakano, K. Shimura, Y. Sakagami, S. Oishi, S. Uchiyama, T. Ohkubo, Y. Kobayashi, N. Fujii, M. Matsuoka, and E. N. Kodama, Antiviral. Res. 2010, 87 $179-186$.

10. J. P. Lalezari, N. C. Bellos, K. Sathasivam, G. J. Richmond, C. J. Cohen, R. A. Myers, Jr., D. H. Henry, C. Raskino, T. Melby, H. Murchison, Y. Zhang, R. Spence, M. L. Greenberg, R. A. Demasi and G. D. Miralles, J. Infect. Dis. 2005, 191, 1155-1163.

11. Y. He, Y. Xiao, H. Song, Q. Liang, D. Ju, X. Chen, H. Lu, W. Jing, S. Jiang and L. Zhang, J. Biol. Chem. 2008, 283, 11126-11134.

12. K. Izumi, E. Kodama, K. Shimura, Y. Sakagami, K. Watanabe, S. Ito, T. Watabe, Y. Terakawa, H. Nishikawa, S. G. Sarafianos, K. Kitaura, S. Oishi, N. Fujii and M. Matsuoka, J. Biol. Chem. 2009, 284, 4914-4920. 
13. J. Cao, L. Bergeron, E. Helseth, M. Thali, H. Repke and J. Sodroski, J. Virol. 1993, 67, 27472755.

14. W. Shu, J. Liu, H. Ji, L. Radigen, S. Jiang and M. Lu, Biochemistry 2000, 39, 1634-1642.

15. D. A. Annis, N. Nazef, C.C. Chuang, M. P. Scott and H. M. Nash, J. Am. Chem. Soc. 2004, 126, 15495-15503.

16. G. C. Adam, C.A. Parish, D. Wisniewski, J. Meng, M. Liu, K. Calati, B. D. Stein, J. Athanasopoulos, P. Liberator, T. Roemer, G. Harris and K. T. Chapman, J. Am. Chem. Soc. 2008, 130, 16704-16710.

17. S. Oishi, S. Ito, H. Nishikawa, K. Watanabe, M. Tanaka, H. Ohno, K. Izumi, Y. Sakagami, E. Kodama, M. Matsuoka and N. Fujii, J. Med. Chem. 2008, 51, 388-391.

18. A. Otaka, M. Nakamura, D. Nameki, E. Kodama, S. Uchiyama, S. Nakamura, H. Nakano, H. Tamamura, Y. Kobayashi, M. Matsuoka and N. Fujii, Angew. Chem. Int. Ed. 2002, 41, 29372940.

19. M. Gochin, R. Savage, S. Hinckley and L. Cai, Biol. Chem. 2006, 387, 477-483.

20. H. Nishikawa, E. Kodama, A. Sakakibara, A. Fukudome, K. Izumi, S. Oishi, N. Fujii, and M. Matsuoka, Antiviral. Res. 2008, 80, 71-76.

21. J. K. Judice, J. Y. Tom, W. Huang, T. Wrin, J. Vennari, C. J. Petropoulos and R. S. McDowell, Proc. Natl. Acad. Sci. USA. 1997, 94, 13426-13430.

22. S. K. Sia, P. A. Carr, A. G. Cochran, V. N. Malashkevich and P. S. Kim, Proc. Natl. Acad. Sci. USA. 2002, 99, 14664-14669.

23. J. J. Dwyer, K. L. Wilson, D. K. Davison, S. A. Freel, J. E. Seedorff, S. A. Wring, N. A. Tvermoes, T. J. Matthews, M. L. Greenberg and M. K. Delmedico, Proc. Natl. Acad. Sci. USA. 2007, 104, 12772-12777.

\section{Footnote}

$\dagger$ Electronic supplementary information (ESI) available: Additional experimental procedures, measurement of CD spectra, bioassays, and MS data. See DOI: 10.1039/c0md00091. 
Figure 1. HIV-1 envelope protein gp41 and the amino acid sequences. (a) Schematic representation of HIV-1 gp41. FP: fusion peptide; TM: transmembrane domain; CP: cytoplasmic tail. (b) Helicalwheel representation of C34/SC35EK and enfuvirtide/T-20EK.

(a) $38 \quad 43$
SGIVQQNNLLRAIEAQQHLLQLTVWGIKQLQARIL
N54 STMGAASMTLTVQARQLLSGIVQQQNNLLRAIEAQQHLLQLTVWGIKQLQQARTL
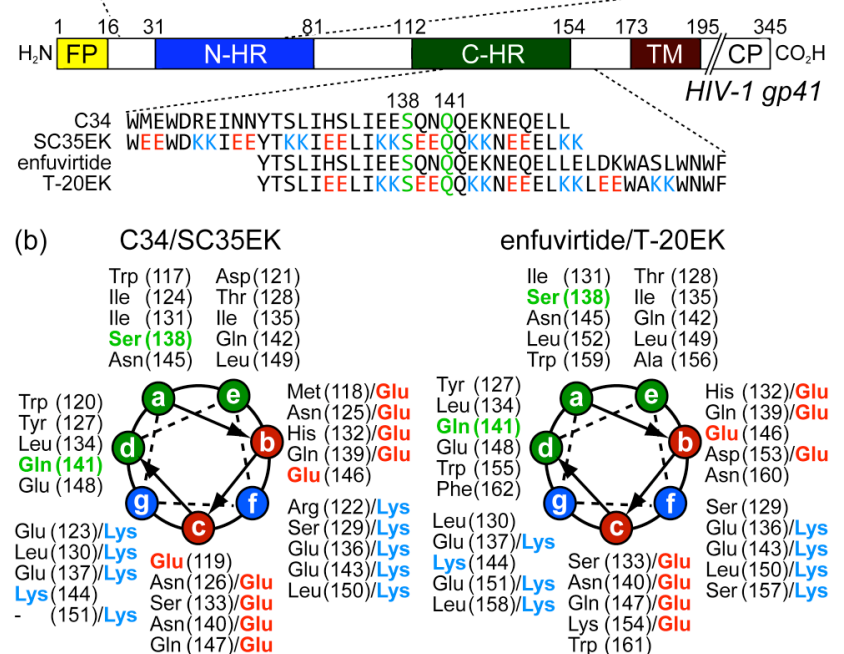

Figure 2. Affinity selection of the HIV-1 fusion inhibitors. (a) Protocol outlining the affinity selection of C-HR peptides using the histidine-tagged N-HR peptide. (b) HPLC profile of a pool of SC35EK derivatives with a single amino acid substitution at position 138 [Cosmosil 5C18 AR-II column; linear 30-40\% MeCN gradient over $40 \mathrm{~min}$; flow rate, $1 \mathrm{~cm}^{3} \mathrm{~min}^{-1}$; detection at $220 \mathrm{~nm}$ ].

(a)

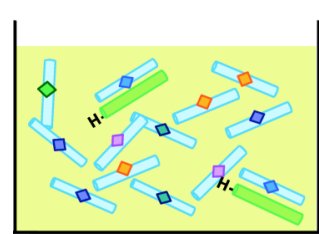

$\diamond$ C-HR peptide H- $\longrightarrow$ His-tagged N-HR peptide
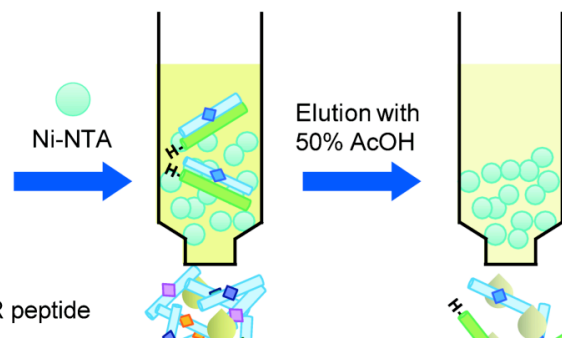

LC-MS analysis (b) $N / Q$

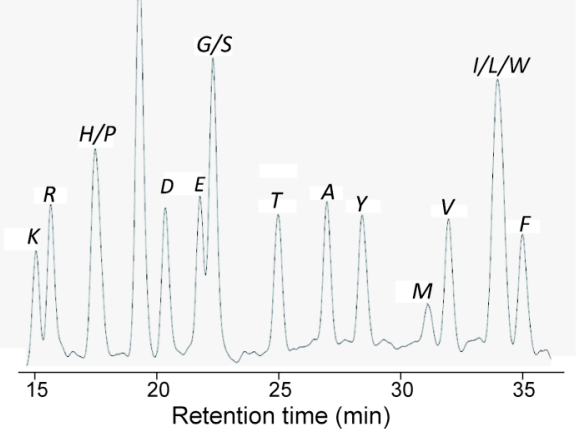


Figure 3. Correlation between the recovery rate and the thermal stability, or the anti-HIV activity. (a, b) SC35EK $\mathrm{S}_{\mathrm{S} 138 \mathrm{x}}$; (c, d) T-20EK $\mathrm{E}_{\mathrm{S} 138 \mathrm{X}}$. $\mathrm{R}^{2}$ values for the correlation of $\mathrm{SC} 35 \mathrm{EK}_{\mathrm{S} 138 \mathrm{X}}$ data were calculated without using the data points of S138R/K/P/D mutants $(n=15)$.
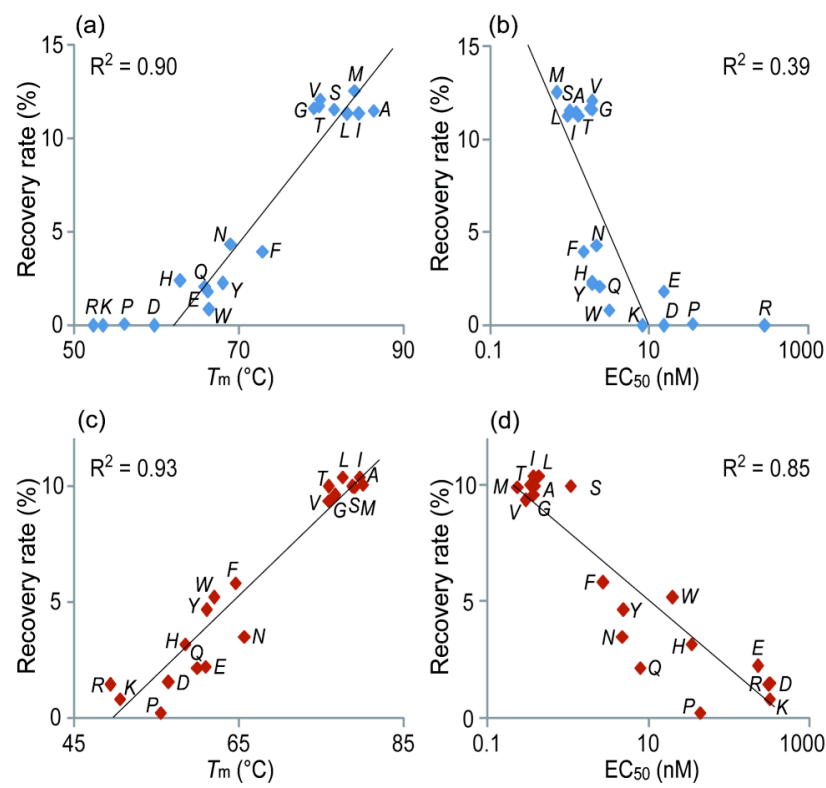
Table 1. Optimization of the affinity selection protocol.

\begin{tabular}{|c|c|c|c|c|c|c|}
\hline \multirow{3}{*}{ X } & Reco & $0)^{a}$ & & & \multirow{3}{*}{$\begin{array}{l}\mathrm{EC}_{50} \\
(\mathrm{nM})^{b}\end{array}$} & \multirow{3}{*}{$\begin{array}{l}T_{\mathrm{m}} \\
\left({ }^{\circ} \mathrm{C}\right)^{c}\end{array}$} \\
\hline & \multicolumn{4}{|c|}{ Concentration of SC35EK $\mathrm{E}_{\mathrm{S} 138 \mathrm{X}}(\mu \mathrm{M})$} & & \\
\hline & 10 & 6 & 1 & 0.6 & & \\
\hline Ser & 22.8 & 19.2 & 11.5 & 5.8 & $1.0 \pm 0.14$ & 81.6 \\
\hline Ala & 30.7 & 22.5 & 11.5 & 5.3 & $1.2 \pm 0.12$ & 86.4 \\
\hline Asp & 0.7 & 0.0 & 0.0 & 4.3 & $15 \pm 3.3$ & 59.7 \\
\hline Glu & 1.3 & 1.0 & 1.8 & 5.1 & $15 \pm 0.69$ & 66.2 \\
\hline Phe & 0.7 & 0.6 & 4.0 & 6.3 & $1.5 \pm 0.10$ & 72.9 \\
\hline Gly & 13.8 & 14.4 & 11.6 & 5.9 & $1.9 \pm 0.26$ & 79.1 \\
\hline His & 0.9 & 0.6 & 2.4 & 5.7 & $1.9 \pm 0.57$ & 62.9 \\
\hline Ile & $4.7^{d}$ & $7.6^{d}$ & $11.3^{d}$ & $6.9^{d}$ & $1.3 \pm 0.54$ & 84.6 \\
\hline Lys & 0.2 & 0.1 & 0.0 & 3.6 & $8.2 \pm 1.7$ & 53.5 \\
\hline Leu & $4.7^{d}$ & $7.6^{d}$ & $11.3^{d}$ & $6.9^{d}$ & $0.93 \pm 0.16$ & 83.2 \\
\hline Met & 8.9 & 13.3 & 12.5 & 6.8 & $0.68 \pm 0.06$ & 84.1 \\
\hline Asn & 1.1 & 0.5 & 4.3 & 6.4 & $2.2 \pm 0.47$ & 69.0 \\
\hline Pro & 0.4 & 0.2 & 0.1 & 4.5 & $35 \pm 9.2$ & 56.1 \\
\hline Gln & 0.9 & 0.5 & 2.1 & 6.1 & $2.4 \pm 0.79$ & 65.9 \\
\hline Arg & 0.3 & 0.1 & 0.0 & 2.5 & $280 \pm 47$ & 52.3 \\
\hline Thr & 9.0 & 12.8 & 11.7 & 5.7 & $1.8 \pm 0.27$ & 79.7 \\
\hline Val & 2.8 & 6.0 & 12.1 & 7.0 & $1.9 \pm 0.64$ & 79.9 \\
\hline $\operatorname{Trp}$ & 0.5 & 0.3 & 0.9 & 6.2 & $3.1 \pm 0.52$ & 66.4 \\
\hline Tyr & 0.5 & 0.4 & 2.3 & 5.9 & $1.9 \pm 0.71$ & 68.0 \\
\hline
\end{tabular}

${ }^{a}$ The recovery rate was determined from the relative detected signals of $[\mathrm{M}+3 \mathrm{H}]^{3+}$ and $[\mathrm{M}+4 \mathrm{H}]^{4+}$ ions by LC-MS analysis. ${ }^{b} \mathrm{EC}_{50}$ was determined as the concentration that blocked HIV-1 $1_{\mathrm{NL} 4-3}$ replication by $50 \%$ in the MAGI assay. To improve the replication kinetics, the D36G mutation, observed in the majority of HIV-1 strains, was introduced into the NL4-3 background used in this study. ${ }^{c} T_{\mathrm{m}}$ values were defined by the midpoint of the thermal unfolding transition state measured by monitoring the molar ellipticity at $222 \mathrm{~nm}$ of $\mathrm{N} 36 / \mathrm{SC} 35 \mathrm{EK}_{\mathrm{S} 138 \mathrm{X}}$ mixture. ${ }^{d}$ Combined yield of $138 \mathrm{I}$ and $138 \mathrm{~L}$ derivatives. 
Table 2. Recovery rate in affinity selection and anti-HIV activity of $\mathrm{T}-20 \mathrm{EK} \mathrm{K}_{\mathrm{S138X}}$, and the thermal stability of the N54-T-20EK ${ }_{\mathrm{S} 138 \mathrm{X}}$ complex.

\begin{tabular}{llllllll}
\hline X & $\begin{array}{l}\text { Recovery } \\
(\%)^{a}\end{array}$ & $\begin{array}{l}\mathrm{EC}_{50} \\
(\mathrm{nM})^{b}\end{array}$ & $\begin{array}{l}T_{\mathrm{m}} \\
\left({ }^{\circ} \mathrm{C}\right)^{c}\end{array}$ & $\mathrm{X}$ & $\begin{array}{l}\text { Recovery } \\
(\%)^{a}\end{array}$ & $\begin{array}{l}\mathrm{EC}_{50} \\
(\mathrm{nM})^{b}\end{array}$ & $\begin{array}{l}T_{\mathrm{m}} \\
\left({ }^{\circ} \mathrm{C}\right)^{c}\end{array}$ \\
\hline Ser & 10.0 & $1.1 \pm 0.2$ & 78.8 & & & & \\
Ala & 10.0 & $0.3 \pm 0.1$ & 80.1 & Met & 9.9 & $0.2 \pm 0.1$ & 79.0 \\
Asp & 1.5 & $330 \pm 96$ & 56.5 & Asn & 3.5 & $4.8 \pm 1.6$ & 65.7 \\
Glu & 2.2 & $230 \pm 31$ & 61.0 & Pro & 0.2 & $44 \pm 8$ & 55.5 \\
Phe & 5.8 & $2.8 \pm 0.2$ & 64.6 & Gln & 2.2 & $7.9 \pm 3.4$ & 60.0 \\
Gly & 9.6 & $0.4 \pm 0.2$ & 76.7 & Arg & 1.5 & $320 \pm 88$ & 49.4 \\
His & 3.2 & $35 \pm 10$ & 58.5 & Thr & 10.0 & $0.4 \pm 0.2$ & 75.9 \\
Ile & $10.4^{d}$ & $0.4 \pm 0.1$ & 79.7 & Val & 9.4 & $0.3 \pm 0.1$ & 76.0 \\
Lys & 0.8 & $330 \pm 67$ & 50.6 & Trp & 5.2 & $20 \pm 9$ & 62.0 \\
Leu & $10.4^{d}$ & $0.4 \pm 0.3$ & 77.6 & Tyr & 4.7 & $5.0 \pm 1.5$ & 61.1 \\
\hline
\end{tabular}

${ }^{a}$ The recovery rate was determined from the relative detected signals of $[\mathrm{M}+3 \mathrm{H}]^{3+}$ and $[\mathrm{M}+4 \mathrm{H}]^{4+}$ ions by LC-MS analysis. ${ }^{b} \mathrm{EC}_{50}$ was determined as the concentration that blocked HIV-1 $1_{\mathrm{NL} 4-3}$ replication by $50 \%$ in the MAGI assay. To improve the replication kinetics, the D36G mutation, observed in the majority of HIV-1 strains, was introduced into the NL4-3 background used in this study. ${ }^{c} T_{\mathrm{m}}$ values were defined by the midpoint of the thermal unfolding transition state measured by monitoring the molar ellipticity at $222 \mathrm{~nm}$ of N54/T-20EK $\mathrm{E}_{\mathrm{S} 138 \mathrm{X}}$ mixture. ${ }^{d}$ Combined yield of $138 \mathrm{I}$ and $138 \mathrm{~L}$ derivatives. 
Table 3. Peptide recovery in affinity selection, anti-HIV activity and thermal stability of the sixhelix bundles of C-HR peptides against enfuvirtide-resistant variants.

\begin{tabular}{lllllll}
\hline & \multicolumn{5}{l}{ SC35EK } \\
\cline { 2 - 7 } & $\begin{array}{l}\text { Recovery } \\
(\%)^{a}\end{array}$ & $\begin{array}{l}\mathrm{EC}_{50} \\
(\mathrm{nM})^{b}\end{array}$ & $\begin{array}{l}T_{\mathrm{m}} \\
\left({ }^{\circ} \mathrm{C}\right)^{c}\end{array}$ & $\begin{array}{l}\text { Recovery } \\
(\%)^{a}\end{array}$ & $\begin{array}{l}\mathrm{EC}_{50} \\
(\mathrm{nM})^{b}\end{array}$ & $\begin{array}{l}T_{\mathrm{m}} \\
\left({ }^{\circ} \mathrm{C}\right)^{c}\end{array}$ \\
\hline$H I V_{V 38 A}$ & & & & \\
Ser & 11.8 & $1.1 \pm 0.3$ & 72.6 & 9.3 & $3.4 \pm 1.4$ & 60.0 \\
Ala & 11.4 & $0.7 \pm 0.2$ & 76.1 & 10.0 & $2.2 \pm 0.8$ & 64.6 \\
Leu & $10.3^{d}$ & $0.8 \pm 0.1$ & 75.0 & $10.1^{d}$ & $3.4 \pm 1.6$ & 57.5 \\
Pro & 0.4 & $340 \pm 61$ & 56.3 & 0.0 & $>1000$ & 49.7 \\
Thr & 10.8 & $0.8 \pm 0.1$ & 70.4 & 8.1 & $28 \pm 12$ & 57.8 \\
Trp & 1.0 & $22 \pm 5.6$ & 64.6 & 7.7 & $>1000$ & 53.2 \\
$H I V_{N 43 D}$ & & & & & \\
Ser & 10.9 & $0.3 \pm 0.1$ & 69.9 & 7.4 & $2.0 \pm 0.4$ & 65.3 \\
Ala & 12.9 & $0.2 \pm 0.1$ & 74.4 & 10.2 & $0.3 \pm 0.1$ & 71.9 \\
Leu & $12.9^{d}$ & $0.2 \pm 0.1$ & 80.0 & $10.8^{d}$ & $0.2 \pm 0.1$ & 74.0 \\
Pro & 0.3 & $130 \pm 52$ & 55.6 & 0.3 & $430 \pm 160$ & 55.0 \\
Thr & 9.4 & $0.3 \pm 0.1$ & 67.5 & 6.1 & $3.7 \pm 0.1$ & 62.4 \\
Trp & 2.4 & $2.7 \pm 0.6$ & 66.0 & 7.6 & $220 \pm 17$ & 61.4
\end{tabular}

${ }^{a}$ The recovery rate was determined from the relative detected signals of $[\mathrm{M}+3 \mathrm{H}]^{3+}$ and $[\mathrm{M}+4 \mathrm{H}]^{4+}$ ions by LC-MS analysis. ${ }^{b} \mathrm{EC}_{50}$ was determined as the concentration that blocked HIV-1 $1_{\mathrm{NL} 4-3}$ replication by $50 \%$ in the MAGI assay. To improve the replication kinetics, the D36G mutation, observed in the majority of HIV-1 strains, was introduced into the NL4-3 background used in this study. ${ }^{c} T_{\mathrm{m}}$ values were defined by the midpoint of the thermal unfolding transition state measured by monitoring the molar ellipticity at $222 \mathrm{~nm}$ of $\mathrm{N} 36_{\mathrm{V}_{38} \mathrm{~A}} / \mathrm{SC} \mathrm{SE} \mathrm{EK}_{\mathrm{S} 138 \mathrm{X}}, \mathrm{N} 36_{\mathrm{N} 43 \mathrm{D}} / \mathrm{SC} 35 \mathrm{EK} \mathrm{S}_{\mathrm{S} 138 \mathrm{X}}$, $\mathrm{N} 4_{\mathrm{V} 38 \mathrm{~A}} / \mathrm{T}-20 \mathrm{EK}_{\mathrm{S} 138 \mathrm{X}}$ or $\mathrm{N} 54_{\mathrm{N} 43 \mathrm{D}} / \mathrm{T}-20 \mathrm{EK}_{\mathrm{S} 138 \mathrm{X}}$ mixture. ${ }^{d}$ Combined yield of $138 \mathrm{I}$ and $138 \mathrm{~L}$ derivatives. 
Table 4. Peptide recovery in affinity selection, anti-HIV activity and thermal stability of the sixhelix bundles of $\mathrm{SC} 35 \mathrm{EK}_{\mathrm{Q} 141 \mathrm{X}}$ and $\mathrm{T}-20 \mathrm{EK}_{\mathrm{Q} 141 \mathrm{X}}$ derivatives.

\begin{tabular}{lllllll}
\hline \multirow{2}{*}{$\mathrm{X}$} & \multicolumn{5}{l}{ SC35EK } & \multicolumn{5}{l}{ T-20EK $\mathrm{E}_{\mathrm{Q} 141 \mathrm{X}}$} \\
\cline { 2 - 7 } & $\begin{array}{l}\text { Recovery } \\
(\%)^{a}\end{array}$ & $\begin{array}{l}\mathrm{EC}_{50} \\
(\mathrm{nM})^{b}\end{array}$ & $\begin{array}{l}T_{\mathrm{m}} \\
\left({ }^{\circ} \mathrm{C}\right)^{c}\end{array}$ & $\begin{array}{l}\text { Recovery } \\
(\%)^{a}\end{array}$ & $\begin{array}{l}\mathrm{EC}_{50} \\
(\mathrm{nM})^{b}\end{array}$ & $\begin{array}{l}T_{\mathrm{m}} \\
\left({ }^{\circ} \mathrm{C}\right)^{c}\end{array}$ \\
\hline Gln & 10.1 & $2.6 \pm 0.3$ & 81.6 & $8.2^{e}$ & $1.5 \pm 0.6$ & 78.8 \\
Ala & 6.6 & $1.6 \pm 0.6$ & 76.1 & 5.6 & $2.7 \pm 0.3$ & 70.4 \\
Asp & 4.5 & $2.9 \pm 0.1$ & 75.1 & 8.2 & $3.5 \pm 0.7$ & 71.4 \\
Glu & 4.3 & $2.4 \pm 0.4$ & 76.2 & $8.2^{e}$ & $3.8 \pm 0.8$ & 71.8 \\
Phe & 5.7 & $2.6 \pm 0.4$ & 76.7 & 5.3 & $2.6 \pm 0.9$ & 64.0 \\
Gly & 3.8 & $2.3 \pm 0.7$ & 71.0 & 3.4 & $3.0 \pm 0.6$ & 66.2 \\
His & 4.3 & $2.0 \pm 0.5$ & 72.6 & 3.7 & $3.0 \pm 0.6$ & 68.4 \\
Ile & $8.2^{d}$ & $2.9 \pm 0.4$ & 79.7 & $10.4^{d}$ & $0.8 \pm 0.3$ & 74.0 \\
Lys & 4.8 & $2.7 \pm 0.5$ & 69.2 & 4.8 & $3.8 \pm 0.3$ & 65.3 \\
Leu & $8.2^{d}$ & $2.7 \pm 0.9$ & 83.8 & $10.4^{d}$ & $0.5 \pm 0.2$ & 77.4 \\
Met & 6.0 & $2.0 \pm 0.3$ & 80.2 & 9.2 & $0.9 \pm 0.1$ & 74.6 \\
Asn & 4.0 & $2.5 \pm 0.5$ & 73.4 & 4.4 & $3.6 \pm 0.7$ & 69.0 \\
Pro & 0.0 & $58 \pm 16$ & 60.2 & 0.3 & $>1000$ & 52.0 \\
Arg & 7.6 & $2.5 \pm 0.1$ & 71.5 & 7.2 & $1.5 \pm 0.3$ & 68.9 \\
Ser & 4.0 & $2.5 \pm 0.7$ & 72.4 & 3.2 & $4.6 \pm 1.4$ & 66.7 \\
Thr & 7.3 & $3.2 \pm 0.6$ & 76.7 & 6.9 & $2.1 \pm 0.5$ & 71.6 \\
Val & 6.2 & $2.2 \pm 0.6$ & 77.7 & 6.1 & $2.9 \pm 0.2$ & 70.5 \\
Trp & 7.1 & $1.7 \pm 0.2$ & 77.1 & 8.1 & $2.5 \pm 0.1$ & 68.8 \\
Tyr & 5.5 & $2.2 \pm 0.6$ & 76.3 & 4.9 & $2.3 \pm 0.9$ & 67.7 \\
\hline
\end{tabular}

${ }^{a}$ The recovery rate was determined from the relative detected signals of $[\mathrm{M}+3 \mathrm{H}]^{3+}$ and $[\mathrm{M}+4 \mathrm{H}]^{4+}$ ions by LC-MS analysis. ${ }^{b} \mathrm{EC}_{50}$ was determined as the concentration that blocked HIV-1 $1_{\mathrm{NL} 4-3}$ replication by $50 \%$ in the MAGI assay. To improve the replication kinetics, the D36G mutation, observed in the majority of HIV-1 strains, was introduced into the NL4-3 background used in this study. ${ }^{c} T_{\mathrm{m}}$ values were defined by the midpoint of the thermal unfolding transition state measured by monitoring the molar ellipticity at $222 \mathrm{~nm}$ of $\mathrm{N} 36 / \mathrm{SC} 35 \mathrm{EK}_{\mathrm{Q} 141}$ or $\mathrm{N} 54 / \mathrm{T}-20 \mathrm{EK} \mathrm{Q}_{141}$ mixture. ${ }^{d}$ Combined yield of 141I and 141L derivatives. ${ }^{e}$ Combined yield of $141 \mathrm{E}$ and $141 \mathrm{Q}$ derivatives. 